\title{
Temporal and regional incidence of carbapenemase- producing Enterobacterales, Switzerland, 2013 to 2018
}

\author{
Alban Ramette ${ }^{1,2}$, Michael Gasser ${ }^{1,2}$, Patrice Nordmann ${ }^{3}$, Reinhard Zbinden ${ }^{4}$, Jacques Schrenzel ${ }^{5}$, Damir Perisa ${ }^{6}$, Andreas \\ Kronenberg ${ }^{1}$ \\ 1. Swiss Centre for Antibiotic Resistance (ANRESIS), Institute for Infectious Diseases, University of Bern, Bern, Switzerland \\ 2. These authors contributed equally to the manuscript \\ 3. Molecular and Medical Microbiology, Department of Medicine, University Fribourg, Fribourg, Switzerland \\ 4. Institute for Medical Microbiology, University of Zurich, Zurich, Switzerland \\ 5. Laboratory of Bacteriology, Geneva University Hospitals, Geneva, Switzerland \\ 6. Federal Office of Public Health, Division of Communicable Diseases, Bern, Switzerland
}

Correspondence: Alban Ramette (alban.ramette@ifik.unibe.ch)

Citation style for this article:

Ramette Alban, Gasser Michael, Nordmann Patrice, Zbinden Reinhard, Schrenzel Jacques, Perisa Damir, Kronenberg Andreas. Temporal and regional incidence of carbapenemase-producing Enterobacterales, Switzerland, 2013 to 2018. Euro Surveill. 2020;26(15):pii=1900760. https://doi.org/10.2807/1560-7917. ES.2021.26.15.1900760

Introduction: In contrast to countries where carbapenemase-producing Enterobacterales (CPE) are endemic, only sporadic cases were reported in Switzerland until 2013. An aggravation of the epidemiological situation in neighbouring European countries indicated the need for a surveillance study in Switzerland. Aim: We aimed to describe CPE distributions in Switzerland and identify epidemiological factors associated with changes in incidence. Methods: Data on all human CPE isolates from 2013 to 2018 were collected by the Swiss Centre for Antibiotic Resistance (ANRESIS) and analysed for temporal and regional trends by Generalised Poisson regression. Isolates associated with infection or colonisation were included in a primary analysis; a secondary analysis included invasive isolates only. Statistical detection of regional clusters was performed with WHONET/SaTScan. Results: We analysed 731 CPE isolates, of which 325 (44.5\%) were associated with screenings and $173(23.7 \%)$ with infections. Yearly detection of CPE isolates increased considerably during the study period from 65 to 212 . The most frequently isolated species were Klebsiella pneumoniae (54\%) and Escherichia coli (28\%). The most frequent genotypes were OXA-48 (43\%), KPC (21\%) and NDM (14\%). In contrast to the French-speaking parts of Switzerland (West, Geneva) where OXA-48 were the predominant genotypes (around 60\%), KPC was the most frequently detected genotype in the Italianspeaking region (63\%). WHONET/SaTScan outbreak detection analysis identified seven clusters in five regions of Switzerland. Conclusions: In a first continuous surveillance of CPE in Switzerland, we found that the epidemiological situation aggravated nationwide and that regional patterns of CPE genotypes mirrored the situation in neighbouring European countries.

\section{Introduction}

Because of their multidrug resistance, carbapenemaseproducing Enterobacterales (CPE) cause increased mortality, morbidity and healthcare costs worldwide [1-3]. As carbapenemase genes are mostly plasmid-encoded and associated with various mobile genetic structures, they are transferred both vertically and horizontally, enabling rapid dissemination $[4,5]$. Based upon amino acid sequence similarities, carbapenemases are classified as members of either the Ambler class A including the $K$. pneumoniae carbapenemases (KPC), class B including Verona integron-encoded metallo$\beta$-lactamase (VIM), Imipenemase (IMP) and New Delhi metallo- $\beta$-lactamase (NDM), or class D including several oxacillinases (OXAs) [6].

In the last decade, infections and colonisations with CPE have increased in the majority of European countries [7]. However, there are large differences regarding surveillance activities and reporting of different carbapenemase genotypes in different regions: KPC endemicity was reported for Greece and Italy, VIM has also been extensively reported in southern Europe, predominantly in Greece, interregional NDM spread has been reported in Poland, Romania and Denmark, and OXA-48 is endemic in Turkey and Malta and widespread in some western European countries (Belgium, France, Spain) $[8,9]$.

In Switzerland, NDM carbapenemase producers were described for the first time in 2009 [10]. KPC [11] and OXA-48 [12] strains were identified one year later. All these reported cases were associated with single occurrences, without evidence of local spread, and were judged as likely introductions via patients from countries with endemic CPE. In 2013, Switzerland participated in the European Survey 
Characteristics of CPE isolates (deduplicated by species), Switzerland, 2013-2018 ( $\mathrm{n}=731$ )

\begin{tabular}{|c|c|c|c|c|c|c|c|c|}
\hline & 2013 & 2014 & 2015 & 2016 & 2017 & 2018 & Total & Total (\%) \\
\hline \multicolumn{9}{|c|}{ Clinical importance } \\
\hline Colonisation & 23 & 22 & 59 & 73 & 63 & 85 & 325 & 44.5 \\
\hline Infection & 12 & 11 & 28 & 31 & 26 & 65 & 173 & 23.7 \\
\hline NA & 30 & 49 & 29 & 38 & 25 & 62 & 233 & 31.9 \\
\hline \multicolumn{9}{|l|}{ Sex } \\
\hline Female & 20 & 29 & 36 & 54 & 51 & 74 & 264 & 36.1 \\
\hline Male & 45 & 52 & 77 & 85 & 63 & 132 & 454 & 62.1 \\
\hline NA & 0 & 1 & 3 & 3 & 0 & 6 & 13 & 1.8 \\
\hline \multicolumn{9}{|c|}{ Age group (years) } \\
\hline $0-4$ & 6 & 1 & 4 & 7 & 5 & 6 & 29 & 4 \\
\hline $5-19$ & 3 & 1 & 4 & 2 & 4 & 8 & 22 & 3 \\
\hline $20-64$ & 29 & 42 & 59 & 68 & 50 & 89 & 337 & 46.1 \\
\hline$\geq 65$ & 27 & 37 & 42 & 64 & 55 & 104 & 329 & 45 \\
\hline NA & 0 & 1 & 7 & 1 & 0 & 5 & 14 & 1.9 \\
\hline \multicolumn{9}{|c|}{ Specimen type } \\
\hline Blood & 3 & 2 & 3 & 3 & 3 & 5 & 19 & 2.6 \\
\hline Wound & 1 & 4 & 7 & 14 & 6 & 11 & 43 & 5.9 \\
\hline Respiratory & 4 & 2 & 10 & 12 & 4 & 8 & 40 & 5.5 \\
\hline Urine & 10 & 26 & 26 & 29 & 24 & 42 & 157 & 21.5 \\
\hline Stool & 22 & 25 & 44 & 73 & 51 & 71 & 286 & 39.1 \\
\hline NA & 25 & 23 & 26 & 11 & 26 & 75 & 186 & 25.4 \\
\hline
\end{tabular}

NA: not available.

a Percentage from the total number of isolates $(n=731)$.

on Carbapenamase-Producing Enterobacteriaceae (EUSCAPE) project [13], which aimed to create a network of reference/expert laboratories able to provide information for monitoring the spread of CPE in Europe. At that time, agreed criteria for submitting CPE isolates to national expert laboratories had been adopted in Switzerland, but several weaknesses in the surveillance were identified such as the lack of a reference laboratory. The EuSCAPE group considered the epidemiological situation regarding CPE in Switzerland as moderate (stage 2b, 'sporadic hospital outbreaks'), although an increasing trend was noticed. Since then, the epidemiological situation has become more critical in France and Italy, countries which border Switzerland [7].

In Switzerland, the number of local CPE outbreaks and imported cases has also increased (e.g. [14-16]) and based on these indications, the Swiss Federal Office of Public Health defined CPE as notifiable pathogens in 2016. However, no systematically collected epidemiological Swiss data have been published until now. The aims of this study were therefore (i) to describe CPE distributions and trends of different genera and genotypes in Switzerland from 2013 to 2018 on a national, regional and hospital level, including the characterisation of individual outbreak clusters, and (ii) to identify epidemiological factors associated with changes in case incidence. Because of major reorganisation of data collection at the national level in 2019, data after 2018 was not included in this analysis.

\section{Methods}

\section{Data acquisition}

In 2013, the Swiss Antibiogram Committee (SAC) of the Swiss Society for Microbiology defined nine Swiss expert laboratories, accredited for characterising CPE on molecular level and connected to the Swiss Centre for Antibiotic Resistance ANRESIS. From 2013 to 2015, all Swiss primary laboratories from the eight regions of Switzerland (national population 8.5 million by the end of 2018) used in ANRESIS were asked to send all suspected human CPE isolates, irrespective of their origin (hospital or outpatient, invasive or colonising), to one of the expert laboratories for confirmation and molecular characterisation (data from individual regions are available on https://www.anresis.ch). For suspicion of CPE, primary laboratories used the guidelines and breakpoints of the given years from the European Committee on Antimicrobial Susceptibility Testing (EUCAST) or the Clinical and Laboratory Standards Institute (CLSI). As hospital outbreaks were rare so far in Switzerland, the Swiss National Center for Infection Control (Swissnoso) published hospital hygiene recommendations in 2017 that specified to perform screenings only for patients who had been hospitalised in foreign countries in the previous 12 months or for individuals with direct contact with CPE carriers [17]. For 
Evolution over time of CPE isolates related to colonisation and infection, Switzerland, 2013-2018 (n = 731)

A. Temporal evolution of CPE isolates

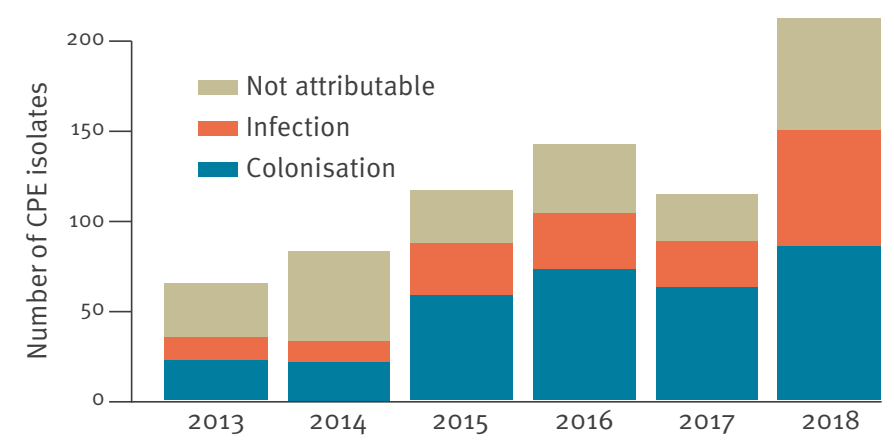

B. By bacterial genus

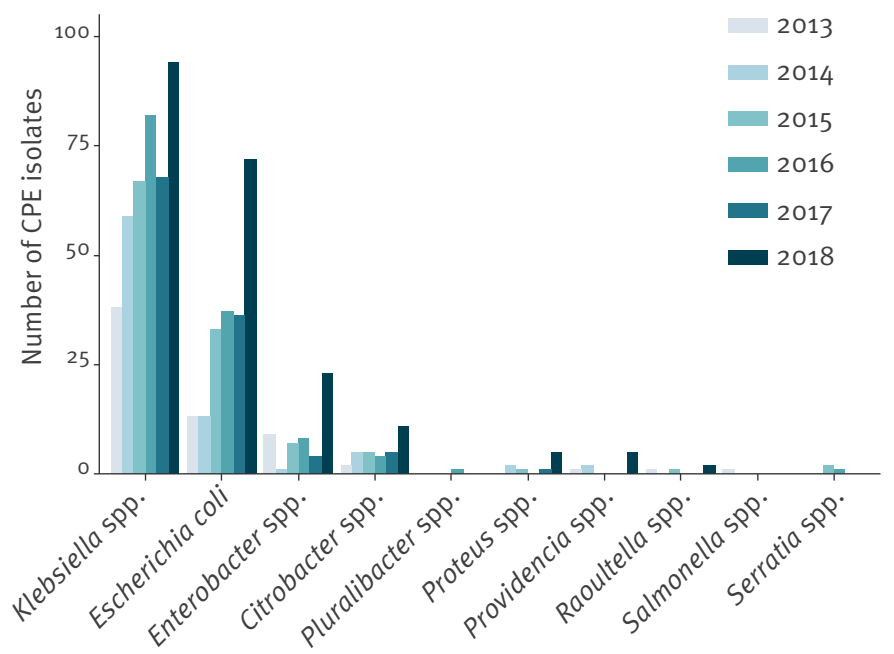

C. By CPE genotype

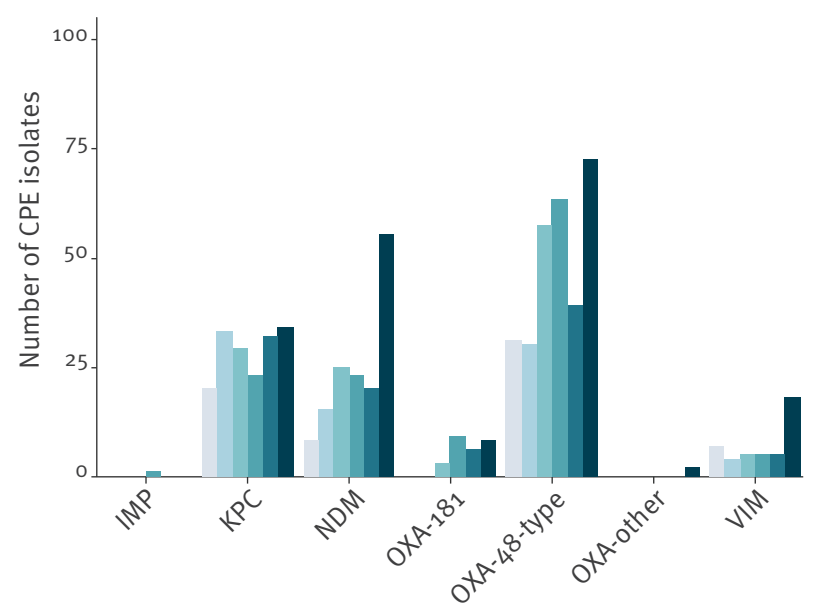

CPE: carbapenemase-producing Enterobacterales.

The category 'OXA-other' includes the few isolates with OXA-232 and OXA-244 genotype (Supplementary Table S2).

each isolate the persons in charge at the hospitals and primary laboratories collated data on specimen type, patient sex, age, place of residence, nationality and possible hospitalisation. The expert laboratories provided information on genotype based on PCR or sequencing. Data from non-carbapenemase-producing carbapenem-resistant Enterobacterales were excluded from further analyses.

From 1 January 2016, reporting of all CPE isolates to the Swiss Federal Office of Public Health (SFOPH) became mandatory and SFOPH started collecting additional epidemiological data on stay abroad in the previous 12 months, prior medical interventions or contacts to other CPE carriers. Finally, the Swiss Centre for Antibiotic Resistance ANRESIS collated all data from 2013 to 2018. Deduplication was performed at the level of bacterial species, by keeping only the first date of occurrence of an isolate for a given year from the same patient. Because of possible horizontal transfer of
CPE genes across bacterial species, a separate deduplication was performed on the CPE genotype level. 'Infection only' isolates were labelled as such according to their clinical classification.

\section{Statistical analyses}

The number of CPE isolates was modelled via Generalised Poisson regression with year, regions, specimen types (stool, blood, respiratory tract, urine, wound, other) and sex as explanatory variables. Robust standard errors for the parameters were calculated according to Cameron and Trivedi [18], p values and $95 \%$ confidence intervals using the parameter estimates and their robust standard errors were calculated accordingly. Population size data was obtained from the Swiss Federal Statistical Office. All analyses and visualisations were done with the $\mathrm{R}$ software environment (version 3.3.2) [19]. 
Total number of CPE isolates per genus and genotype, Switzerland, 2013-2018 ( $\mathrm{n}=682)$

\begin{tabular}{|c|c|c|c|c|c|c|c|c|c|c|c|c|c|c|c|c|}
\hline & & \multirow{2}{*}{\multicolumn{2}{|c|}{$\begin{array}{c}\text { Klebsiella spp. } \\
1\end{array}$}} & \multirow{2}{*}{\multicolumn{2}{|c|}{$\begin{array}{c}\begin{array}{c}\text { Escherichia } \\
\text { coli }\end{array} \\
0 \\
\end{array}$}} & \multicolumn{2}{|c|}{ Enterobacter spp. } & \multicolumn{2}{|c|}{ Citrobacter spp. } & \multicolumn{2}{|c|}{ Proteus spp. } & \multicolumn{2}{|c|}{ Providencia spp. } & \multicolumn{2}{|c|}{ Others } & Total \\
\hline \multirow{2}{*}{ IMP } & $\mathrm{n}$ & & & & & \multicolumn{2}{|c|}{0} & \multicolumn{2}{|c|}{0} & \multicolumn{2}{|c|}{0} & \multicolumn{2}{|c|}{0} & \multicolumn{2}{|c|}{0} & 1 \\
\hline & $\%$ & 100 & $<1$ & \multicolumn{2}{|c|}{0} & \multicolumn{2}{|c|}{0} & \multicolumn{2}{|c|}{0} & \multicolumn{2}{|c|}{0} & \multicolumn{2}{|c|}{0} & \multicolumn{2}{|c|}{0} & 0 \\
\hline \multirow{2}{*}{ KPC } & $\mathrm{n}$ & \multicolumn{2}{|c|}{153} & \multicolumn{2}{|c|}{9} & \multicolumn{2}{|c|}{5} & \multicolumn{2}{|c|}{1} & \multicolumn{2}{|c|}{0} & \multicolumn{2}{|c|}{1} & \multicolumn{2}{|c|}{2} & 171 \\
\hline & $\%$ & 90 & 40 & 5 & 5 & 3 & 9 & $<1$ & 3 & 0 & 0 & $<1$ & 14 & 1 & 17 & 25 \\
\hline \multirow{2}{*}{ NDM } & $\mathrm{n}$ & \multicolumn{2}{|c|}{66} & \multicolumn{2}{|c|}{41} & \multicolumn{2}{|c|}{21} & \multicolumn{2}{|c|}{9} & & & & & & 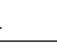 & 146 \\
\hline & $\%$ & 45 & 17 & 28 & 22 & 14 & 40 & 6 & 28 & 2 & 33 & 3 & 71 & $\ll 1$ & 8 & 21 \\
\hline OXA- & $\mathrm{n}$ & & & & & & & & & & & & & & 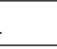 & 26 \\
\hline 181 & $\%$ & 27 & 2 & 65 & 9 & & & 4 & 3 & & & & & 4 & 8 & 4 \\
\hline OXA- & $\mathrm{n}$ & & & & & & & & & & & & & & 5 & 292 \\
\hline 48 & $\%$ & 50 & 38 & 39 & 61 & 5 & 28 & 5 & 41 & & & $<1$ & 14 & 2 & 50 & 43 \\
\hline OXA- & $\mathrm{n}$ & & & & & & & & & & & & & & & 2 \\
\hline other & $\%$ & 50 & $<1$ & 50 & $<1$ & & & & & & & & & & 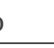 & 0 \\
\hline VIM & $\mathrm{n}$ & & & & & & & & & & & & & & 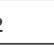 & 44 \\
\hline 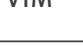 & $\%$ & 25 & 3 & 11 & 3 & 27 & 23 & 18 & 25 & 14 & 67 & & & 5 & 17 & 7 \\
\hline Tatal & $\mathrm{n}$ & & & & & & & & & & & & & & 2 & 682 \\
\hline Total & $\%$ & & & & & & & & & & & & & & & 100 \\
\hline
\end{tabular}

CPE: carbapenemase-producing Enterobacterales; IMP: Imipenemase; KPC: Klebsiella pneumoniae carbapenemase; NDM: New Delhi metallo$\beta$-lactamase; OXA: Oxacillinase; VIM: Verona integron-encoded metallo- $\beta$-lactamase.

Left cell: Percentages relative to total count per row; right cell: Percentages relative to total count per column.

The category 'others' includes Pluralibacter spp., Raoultella spp., Salmonella spp., Serratia spp. and unknowns. The category 'OXA-other' includes the OXA-232 and OXA-244 genotypes. For a non-aggregated view of species and genotypes, see Supplementary Table S3.

\section{Cluster analyses}

Cluster analyses were performed with WHONET 5.6 which embeds the SaTScan software. Simulated prospective space-time permutation scan statistics were calculated [20] with a baseline of 365 days. The maximum cluster length was set to 100 days. Recurrence intervals (i.e. the timespan in which an observed cluster can be observed once by chance) were calculated using 9,999 Monte Carlo simulations and considered significant if they were equal to or longer than 365 days. Single-case clusters containing different species were not considered. Isolates that were part of significant clusters were inspected at the level of raw data in detail. We then contacted infectiologists from the hospitals in which clusters were detected to confirm the identification of local outbreaks.

\section{Sensitivity analyses}

Because the laboratories that sent CPE data in the period 2016 to 2018 (SFOPH data; 22 laboratories) did not perfectly match those that sent data to the expert network before (SAC data 2013-2015; 30 laboratories), a sensitivity analysis was performed that considered only the 18 laboratories that sent data during the whole study period. In addition, a sensitivity analysis was performed by considering infections only, i.e. by removing CPE isolates associated with CPE screenings.

\section{Ethical statement}

This study was based on national surveillance data submitted to the Swiss Centre for Antibiotic Resistance ANRESIS. Because of the anonymous nature of the data, neither ethical approval nor written informed consent from patients were required.

\section{Results}

After deduplication by species, a total of 731 single CPE isolates from 34 primary laboratories were recorded in Switzerland from 2013 to 2018 (Table 1). Among them, $325(45 \%)$ and $173(24 \%)$ isolates were associated with colonisation and infection, respectively, and for the remaining 233 this information was not available. A total of $454(62 \%)$ isolates were from male patients and 666 (91\%) were from patients older than 20 years. Of all characterised isolates, 286 (39\%) were from stool, followed by urine $(157 ; 21 \%)$, respiratory tract $(40 ; 6 \%)$, and 19 (3\%) from blood samples. In another deduplication which was performed by genotype only, 682 CPE isolates were counted.

From 2013 to 2018, the total number of CPE isolates increased more than threefold at the national level and went from 65 to $212(+226 \%)$ yearly isolates (Figure $1 \mathrm{~A})$. While the total number seemed to have stabilised from 2015 to 2017 at around 120 CPE isolates yearly, the number increased drastically from 114 CPE isolates in 2017 to 212 in 2018 (+86\%). This increase was to a considerable extent due to a larger number of CPEassociated infections in 2018 (increase from 26 to 65 isolates, $+150 \%)$. In contrast, the number of isolates related to colonisation remained stable after 2014 .

CPE were most frequently encountered in Klebsiella spp. (56\% overall), Escherichia coli (27\%) 


\section{FIGURE 2}

Geographical distribution of CPE genotypes per 100,000 inhabitants, Switzerland, 2013-2018 $(\mathrm{n}=682)$
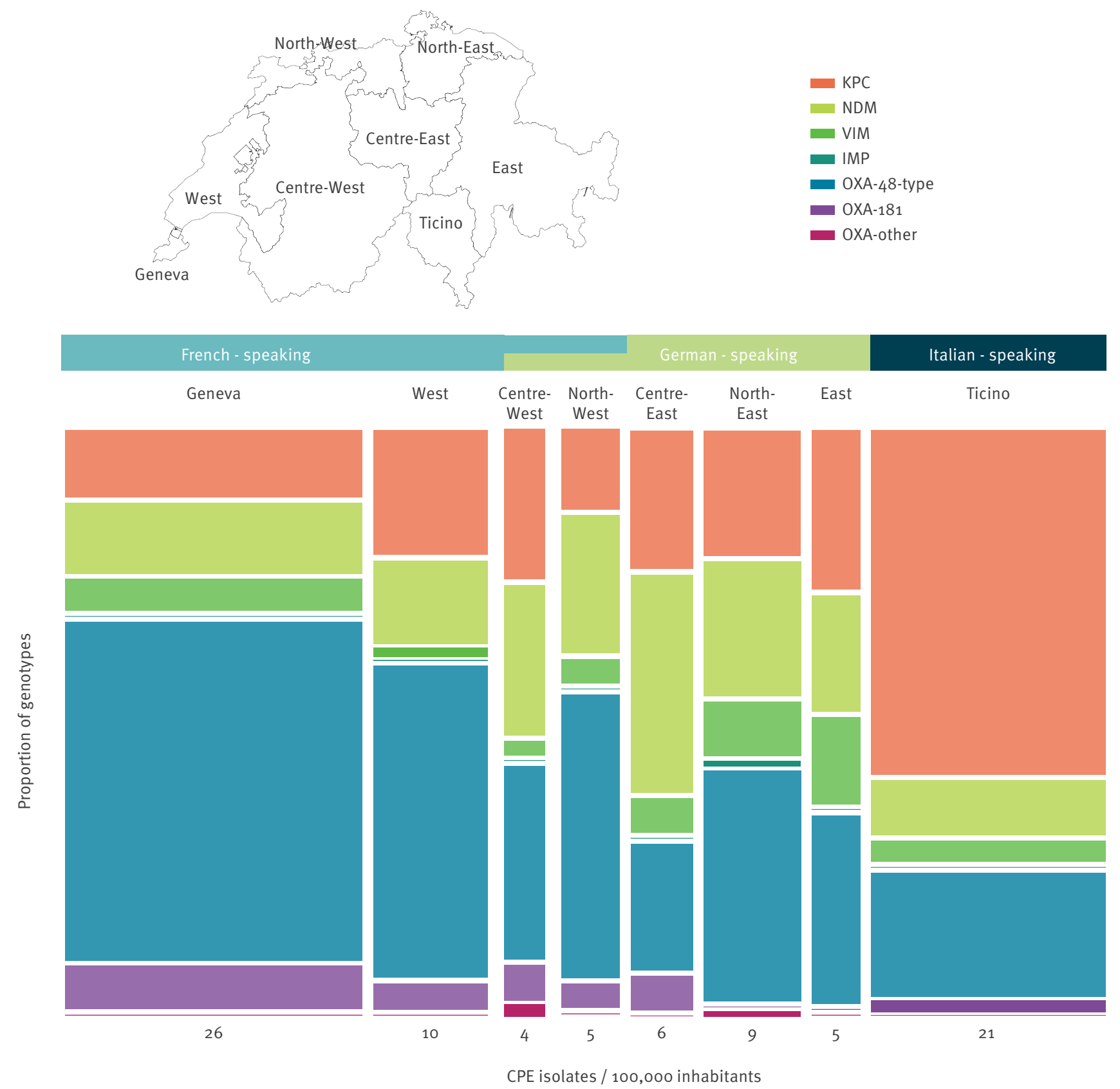

CPE: carbapenemase-producing Enterobacterales; IMP: Imipenemase; KPC: Klebsiella pneumoniae carbapenemase; NDM: New Delhi metallo$\beta$-lactamase; OXA: Oxacillinase; VIM: Verona integron-encoded metallo- $\beta$-lactamase.

The mean for the whole country was eight isolates per 100,000 inhabitants over the whole study period.

and Enterobacter spp. (8\%) (Figure 1B, Table 2). Relative proportions of $E$. coli increased from $20 \%$ in 2013 to $34 \%$ in 2018, whereas Klebsiella spp. decreased from $59 \%$ to $44 \%$. Enterobacter spp. decreased from $14 \%$ to $11 \%$ (Supplementary Table $\mathrm{S} 1$ ). An increase in CPE numbers was observed in all genera in 2018 compared with 2017: from 68 to 94 isolates $(+38.2 \%)$ for Klebsiella spp., from 36 to 72 isolates (+100\%) for $E$. coli, from four to $23(+475 \%)$ for Enterobacter spp., but also for other, usually less frequently observed CPE genera such as Citrobacter spp. $(+120 \%$ from five to 11 isolates) or Proteus spp. (+400\%, from one to five isolates). The most frequent carbapenemase genotypes were OXA-48 (43\%; Figure 1 C, Table 2), KPC (25\%) and NDM (21\%). Only a few VIM-like, OXA-181 and IMP-like carbapenemases were reported (6\%, 4\% and $<1 \%$, respectively; Figure $1 \mathrm{C}$, Table 2$)$. The number of isolates was higher in 2018 than in 2017 for all major genotypes (Figure $1 \mathrm{C}$, Supplementary Table S2). In 2018, OXA-48 producers increased from 39 to 
Factors affecting the number of CPE isolates in a multivariable Poisson regression Switzerland, 2013-2018 (n = 731)

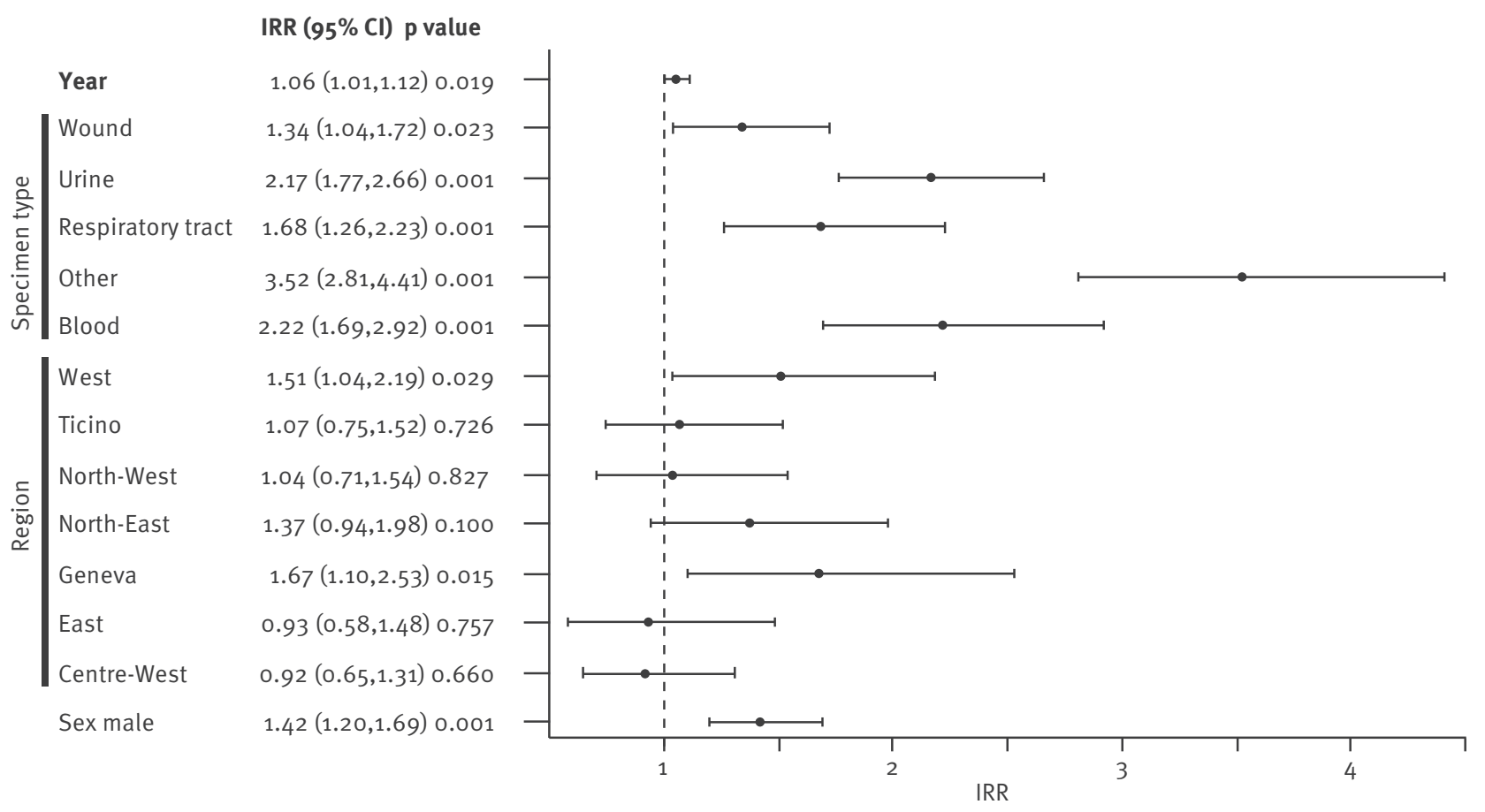

$\mathrm{Cl}$ : confidence interval; CPE: carbapenemase-producing Enterobacterales; IRR: incident rate ratio.

Levels of reference were stool for the factor sample type, the Centre-East region (for the factor region) and female (for the factor sex).

72 isolates (+85\%), NDM-like producers from 20 to 55 isolates (+175\%) and VIM increased from five to 18 isolates $(+260 \%)$. The predominant genotype in $E$. coli was OXA-48 (61\%), whereas most Klebsiella spp. were of the KPC (40\%) and the OXA-48 (38\%) genotypes, while $17 \%$ of Klebsiella spp. were NDM genotypes (Table 2 ).

The total number of CPE isolates increased over time in every Swiss region, except in the Centre-East and the Geneva region (Supplementary Table S4). The highest numbers of CPE isolates per 100,000 inhabitants were identified in the French-speaking region of Geneva and the Italian-speaking region of Ticino (Figure 2). In the latter area, the predominant genotype was KPC (63\%), whereas in the French-speaking part including Geneva and the West, most isolates consisted of OXA-48 genotype ( $61 \%$ and $57 \%$, respectively). In the predominantly German-speaking parts, OXA-48 was the most abundant genotype in all areas, except in the Centre-East region where NDM was the most abundant genotype (40\%).

\section{Multivariable analysis}

Multivariable analysis of regional and temporal CPE trends confirmed a temporal increase in total number. Compared with stool samples, all other types of specimen (wound, urine, respiratory tract, blood and others) were more likely to be associated with higher number of CPE isolates. The incidence was 1.42 higher in male than in female patients. The incidence rate ratio was 1.67 times higher in the Geneva region than in the Centre-East region where the number of CPE isolates was smallest (Figure 3).

\section{Cluster analysis}

All 682 deduplicated genotypes from 2013 to 2018 were included in the simulated prospective cluster analysis by WHONET-SatScan. In five of eight regions of Switzerland, significant clusters were identified (i.e. the recurrence interval was $>365$ days), resulting in a total of seven clusters (Table 3). In 2013 and 2014, only KPC clusters were detected, while thereafter, OXA-48 was the predominant genotype. All clusters had been identified by the responsible hospital infectiologists directly after their occurrence. Three of them were confirmed as locally detected outbreaks by genetic analyses, in the other three, no further investigations were performed because, among other reasons, they were considered as imported cases.

\section{Sensitivity analysis}

The statistical analyses described above for the full dataset were repeated with the 166 isolates originating from infections only. Compositions of genotypes and species and the geographical distribution were largely identical in the two analyses (Supplementary

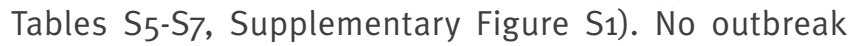


TABLE 3

Characterisation of CPE clusters detected by the automated WHONET-SatScan system, Switzerland, 2013-2018 (n = 682)

\begin{tabular}{|c|c|c|c|c|c|c|c|}
\hline Signal period & $\begin{array}{c}\text { 22-28 Mar } \\
2013\end{array}$ & $\begin{array}{c}27 \text { Sep-11 Oct } \\
2013\end{array}$ & $\begin{array}{c}2 \text { May-12 Jun } \\
2014\end{array}$ & $\begin{array}{l}20 \text { Mar-4 May } \\
2015\end{array}$ & 1 Dec 2015 & $\begin{array}{c}15-23 \text { Feb } \\
2018\end{array}$ & 25-28 Apr 2018 \\
\hline Genotype & $\mathrm{KPC}-2$ & $\mathrm{KPC}$ & $K P C-2, K P C-3$ & OXA-48 & OXA-48 & OXA-48 & VIM \\
\hline Number observed & 3 & 4 & 7 & 8 & 10 & 6 & 3 \\
\hline Number expected & 0.5 & 0.55 & 1.32 & 1.94 & 2.44 & 0.91 & 0.13 \\
\hline Recurrence interval & 559 & 588 & 2,113 & 667 & 16,540 & 720 & 655 \\
\hline Region & East & North-East & Centre-East & North-East & Geneva & West & North-East \\
\hline $\begin{array}{l}\text { Number of hospitals } \\
\text { involved }\end{array}$ & 1 & 2 & 1 & 1 & 1 & 1 or 2 & 1 \\
\hline $\begin{array}{l}\text { Number of patients } \\
\text { involved }\end{array}$ & 3 & 4 & 7 & 6 & 5 & 3 & 3 \\
\hline $\begin{array}{l}\text { Number of species } \\
\text { involved }\end{array}$ & 1 & 2 & 1 & 4 & 4 & 3 & 1 \\
\hline Confirmation status ${ }^{a}$ & $\begin{array}{l}\text { Cluster and } \\
\text { outbreak } \\
\text { confirmed }\end{array}$ & $\begin{array}{l}\text { Cluster } \\
\text { confirmed }\end{array}$ & $\begin{array}{l}\text { Cluster } \\
\text { confirmed, } \\
\text { outbreak } \\
\text { excluded }\end{array}$ & $\begin{array}{l}\text { Cluster and } \\
\text { outbreak } \\
\text { confirmed }\end{array}$ & $\begin{array}{l}\text { Cluster } \\
\text { confirmed }\end{array}$ & $\begin{array}{l}\text { Cluster } \\
\text { confirmed }\end{array}$ & $\begin{array}{l}\text { Cluster and } \\
\text { outbreak } \\
\text { confirmed }\end{array}$ \\
\hline
\end{tabular}

CPE: carbapenemase-producing Enterobacterales; KPC: K. pneumoniae carbapenemase; OXA: Oxacillinase; VIM: Verona integron-encoded metallo- $\beta$-lactamase.

a Confirmation status indicates whether an accumulation of cases was detected in the hospital but no further investigation was performed ('cluster confirmed'), whether a local outbreak was confirmed by genetic analyses ('Cluster and outbreak confirmed') or whether an accumulation of cases was detected but a local transmission was excluded by genetic analyses ('Cluster confirmed, outbreak excluded').

was detected in a cluster analysis by WHONET-SatScan considering only isolates from infections.

When considering the 18 laboratories that contributed CPE data in both the SAC database (2013-2015) and the SFOPH database (2016-2018), a total of 392 of 731 CPE species (53.6\%), consisting of 378 (55.4\%) of all 682 CPE genotypes, were retained and analysed. Results and trends reported from this analysis (Supplementary Figure S2) were largely congruent with the results described above (Figure 3). Noticeably, with the reduced dataset, the factor 'year' was not significant any more $(p=0.240)$.

\section{Discussion}

The consolidation of CPE data from multiple, validated sources allowed us for the first time to study CPE rates over an extended period of time (2013-2018) in Switzerland. Hence, we examined not only the incidence and distribution of CPE on a national scale but also clustering at the regional and hospital level. The number of yearly detected CPE isolates has more than tripled during the study period. This increase could be confirmed, albeit to a lesser extent, in two subanalyses using infections only or considering laboratories participating throughout the whole study period, suggesting that the observed increase in isolates may not only be due to more frequent testing and/or reporting.

The increase in Switzerland mirrors the development in Europe, where a prevailing dissemination of CPE in healthcare systems has been described for 2010 to 2018 [7]. A closer look at the countries bordering Switzerland shows that the situation in Germany remained on an intermediate level (regional spread) between 2010 and
2018, whereas Italy entered in an endemic situation in 2013 and France reached a stage of inter-regional spread in $2014[7,8]$. The strong increase in Switzerland after 2017 may therefore be related to the epidemic situation in these neighbouring countries. In addition, the situation in Switzerland is probably affected by the deteriorating epidemiological situation in countries beyond its neighbourhood, from where a significant influx of CPE cases can be expected through (medical) tourism and migration. CPE isolates associated with $E$. coli doubled from 2017 to 2018 in Switzerland, but also isolates related to less common genera such as Enterobacter spp. and Citrobacter spp. increased substantially in the last year of our study. In particular the increased isolation of $E$. coli is worrisome and may indicate a dissemination of CPE in the community (not examined in our study), as already described in France [9]. Such a development would be of special concern as the spread of carbapenemase-producing bacteria in the community is more difficult to control than a spread in the hospital environment [5].

As reported from most European countries $[13,21]$, Klebsiella pneumoniae was the most frequently observed CPE species in Switzerland. However, compared with other species, the increase of this typically nosocomial microorganism [21] was modest. Molecular data indicate that OXA-48, KPC and NDM types are the most prevalent genotypes in Switzerland. A clear majority of isolates belonged to the OXA-48 and OXA-48-like genotypes, which disseminated over all parts of Switzerland and most distinctly over the western region of Geneva. Possible explanations are the internationality of Geneva and the cross-border exchanges with Switzerland's western neighbour 
France where cases of OXA-48 and OXA-48-like genotypes have increased from regional to inter-regional spread since 2013 [8]. As OXA-48 and OXA-48-like genotypes do not exhibit high resistance levels to carbapenems, their detection is considered difficult and their real incidence could even be higher [5].

The stable occurrence of the KPC genotype goes along with the low increase in K. pneumoniae (as KPC was predominately found in $K$. pneumoniae). The incidence rates of KPC were highest in the Italian-speaking region of Ticino. This observation reflects well the situation in neighbouring Italy, where KPC-producing K. pneumoniae became endemic already in 2010 [8].

NDM increased considerably in 2018 in all regions of the country. This finding fits well with the worldwide prevalence of this genotype $[22,23]$. Equally remarkable was the recent sharp increase in VIM in Enterobacterales. However, the situation for VIM has to be monitored further in order to conclude whether it reaches an endemic stage as in southern Europe [8].

In the cluster analysis, the majority of detected outbreaks were related to the two most abundant genotypes OXA-48 and KPC. The shift from KPC- to OXA-48 clusters in 2014 and 2015 fits well with the increase in the OXA-48 isolates during the study period. Three of seven clusters detected by SatScan were confirmed as in-hospital outbreaks using genetic analyses conducted by local hospital infectiologists. Hence, we could demonstrate that a cluster analysis may facilitate the identification of real outbreaks. However, we suggest that such an approach needs to be done in combination with in-depth molecular typing technologies such as whole genome sequencing [24] in order to confirm cases that are genetically related. Other requirements for an accurate detection system for future outbreaks are the strict use of screening algorithms as published in 2017 by Swissnoso [17] and that all CPE isolates are sent to the same Swiss national reference laboratory (as done since 2019), which allows detailed and timely genetic analysis and thus the detection of potential inter-hospital transmission.

Limitations of our study include the fact that clinical and epidemiological data were not available throughout the whole study, e.g. not every isolate could be associated with infection or colonisation, and information about whether patients had stayed abroad was only available for some isolates after 2016. In addition, increased awareness (reflected in a change to mandatory reporting in 2016) could have artificially increased the number of detected CPE isolates during the study period. We believe, however, that our reported trends are robust, as the detected increase was confirmed by two subanalyses, which restricted the dataset to laboratories participating throughout the whole study period or to invasive isolates only.
The strengths of our study are that the analyses were based on data collected regularly over six consecutive years, covering all cultural and linguistic areas of Switzerland and that they included reports from the largest hospitals and laboratories nationally. With the inclusion of data from university, cantonal and regional hospitals, we can ensure that most hospitalised patients in Switzerland were represented.

\section{Conclusion}

Our data describe a severalfold increase in incidence of all major CPE genotypes across all regions of Switzerland from 2013 to 2018. With OXA-48 as the predominant genotype in the western parts (bordering France) and KPC in the southern part (bordering Italy), the distribution within Switzerland mirrors the situation in western Europe. According to the trends in neighbouring European countries, we may also witness further spread of OXA-48 and NDM-producing $E$. coli and stabilisation or decrease of KPC producers. Owing to the current mandatory reporting scheme, a continuous surveillance of the situation in Switzerland is achieved, and a first important step has thus been taken to follow the progression of CPE incidence with high spatial and temporal resolution.

\section{Acknowledgements}

We thank the accredited laboratories of the Swiss Antibiogram Committee (SAC), and the Swiss Federal Office of Public Health (SFOPH) for providing data and financial support. We thank all the laboratories and hospitals which enabled this study by providing CPE data and by answering questions related to outbreak investigations.

Funding statement: This work is financially supported by the Swiss Federal Office of Public Health and the Institute for Infectious Diseases of the University Bern, Switzerland.

\section{Conflict of interest}

None declared.

\section{Authors' contributions}

$A R, M G$ and $A K$ determined the content and objectives of the analyses. AR, MG analysed the epidemiological data with advice from DP. Epidemiological trend interpretation was done with guidance from PN, RZ, and JS. AR, MG and AK drafted the manuscript together. All authors contributed to the revisions of the draft manuscript and approved the final version.

\section{References}

1. Xu M, Fu Y, Kong H, Chen X, Chen Y, Li L, et al. Bloodstream infections caused by Klebsiella pneumoniae: prevalence of blaKPC, virulence factors and their impacts on clinical outcome. BMC Infect Dis. 2018;18(1):358. https://doi. org/10.1186/s12879-018-3263-x PMID: 30064360

2. Xu L, Sun X, MaX. Systematic review and meta-analysis of mortality of patients infected with carbapenem-resistant Klebsiella pneumoniae. Ann Clin Microbiol Antimicrob. 2017;16(1):18. https://doi.org/10.1186/s12941-017-0191-3 PMID: 28356109 
3. Wilson H, Török ME. Extended-spectrum $\beta$-lactamaseproducing and carbapenemase-producing Enterobacteriaceae. Microb Genom. 2018;4(7):eoo0197. https://doi.org/10.1099/ mgen.0.000197 PMID: 30035710

4. Hardiman CA, Weingarten RA, Conlan S, Khil P, Dekker JP, Mathers AJ, et al. Horizontal transfer of carbapenemaseencoding plasmids and comparison with hospital epidemiology data. Antimicrob Agents Chemother. 2016;60(8):4910-9. https://doi.org/10.1128/AAC.00014-16 PMID: 27270289

5. Nordmann P, Dortet L, Poirel L. Carbapenem resistance in Enterobacteriaceae: here is the storm! Trends Mol Med. 2012;18(5):263-72. https://doi.org/10.1016/j. molmed.2012.03.003 PMID: 22480775

6. Queenan AM, Bush K. Carbapenemases: the versatile betalactamases. Clin Microbiol Rev. 2007;20(3):440-58. https:// doi.org/10.1128/CMR.00001-07 PMID: 17630334

7. Brolund A, Lagerqvist N, Byfors S, Struelens MJ, Monnet $\mathrm{DL}$, Albiger B, et al. Worsening epidemiological situation of carbapenemase-producing Enterobacteriaceae in Europe, assessment by national experts from 37 countries, July 2018. Euro Surveill. 2019;24(9):1900123. https://doi. org/10.2807/1560-7917.ES.2019.24.9.1900123 PMID: 30862330

8. Albiger B, Glasner C, Struelens MJ, Grundmann H, Monnet DL, European Survey of Carbapenemase-Producing Enterobacteriaceae (EuSCAPE) working group. Carbapenemaseproducing Enterobacteriaceae in Europe: assessment by national experts from 38 countries, May 2015. Euro Surveill. 2015;20(45):30062. https://doi.org/10.2807/1560-7917. ES.2015.20.45.30062 PMID: 26675038

9. Dortet L, Cuzon G, Ponties V, Nordmann P. Trends in carbapenemase-producing Enterobacteriaceae, France, 2012 to 2014. Euro Surveill. 2017;22(6):30461. https://doi. org/10.2807/1560-7917.ES.2017.22.6.30461 PMID: 28205502

10. Poirel L, Schrenzel J, Cherkaoui A, Bernabeu S, Renzi G, Nordmann P. Molecular analysis of NDM-1-producing enterobacterial isolates from Geneva, Switzerland. J Antimicrob Chemother. 2011;66(8):1730-3. https://doi.org/10.1093/jac/ dkr174 PMID: 21628303

11. Poirel L, Lienhard R, Potron A, Malinverni R, Siegrist $H H$, Nordmann P. Plasmid-mediated carbapenem-hydrolysing $\beta$-lactamase KPC-2 in a Klebsiella pneumoniae isolate from Switzerland. J Antimicrob Chemother. 2011;66(3):675-6. https://doi.org/10.1093/jac/dkq499 PMID: 21193473

12. Poirel L, Potron A, Nordmann P. OXA-48-like carbapenemases: the phantom menace. J Antimicrob Chemother. 2012;67(7):1597606. https://doi.org/10.1093/jac/dkS121 PMID: 22499996

13. Glasner C, Albiger B, Buist G, Tambić Andrasević A, Canton R, Carmeli Y, et al. Carbapenemase-producing Enterobacteriaceae in Europe: a survey among national experts from 39 countries, February 2013. Euro Surveill. 2013;18(28):20525. https://doi. org/10.2807/1560-7917.ES2013.18.28.20525 PMID: 23870096

14. Ruppé E, Olearo F, Pires D, Baud D, Renzi G, Cherkaoui A, et al. Clonal or not clonal? Investigating hospital outbreaks of KPC-producing Klebsiella pneumoniae with whole-genome sequencing. Clin Microbiol Infect. 2017;23(7):470-5. https:// doi.org/10.1016/j.cmi.2017.01.015 PMID: 28143787

15. Lemmenmeier E, Kohler P, Bruderer T, Goldenberger D, Kleger GR, Schlegel M. First documented outbreak of KPC-2-producing Klebsiella pneumoniae in Switzerland: infection control measures and clinical management. Infection. 2014;42(3):52934. https://doi.org/10.1007/S15010-013-0578-9 PMID: 24477886

16. Mueller L, Ottiger C, Demord A, Poirel L, Nordmann P. Multiple colonization with carbapenem-resistant Gram-negative bacteria acquired in India and transferred to Switzerland. Infection. 2019;47(4):669-71. https://doi.org/10.1007/s15010019-01307-4 PMID: 30972715

17. Olearo F, Pires D, Camus V, Harbart S. Carbapenemaseproduzierende Enterobakterien (CPE): Strategien zur Überwachung und Betreuung von Patienten mit CPE. [Carbapenemase-producing Enterobacteria (CPE): Strategies for monitoring and care of patients with CPE]. Zurich: Swissnoso Bulletin. 2017/05. German. Available from: https://www.swissnoso.ch/ fileadmin/swissnoso/Dokumente/6 Publikationen/ Bulletin_Artikel_D/170606_Olearoetal_DE.pdf

18. Cameron AC, Trivedi PK. Microeconometrics using stata. College Station, Texas: Stata Press; 2009. https://doi. org/10.1111/1475-4932.12006

19. R Core Team. R: A language and environment for statistical computing. Vienna: R Foundation for Statistical Computing; 2019. Available from: https://www.R-project.org

20. Kulldorff M, Heffernan R, Hartman J, Assunção R, Mostashari F. A space-time permutation scan statistic for disease outbreak detection. PLoS Med. 2005;2(3):e59. https://doi.org/10.1371/ journal.pmed.0020059 PMID: 15719066

21. Grundmann H, Glasner C, Albiger B, Aanensen DM, Tomlinson CT, Andrasević AT, et al. Occurrence of carbapenemaseproducing Klebsiella pneumoniae and Escherichia coli in the European survey of carbapenemase-producing Enterobacteriaceae (EUSCAPE): a prospective, multinational study. Lancet Infect Dis. 2017;17(2):153-63. https://doi. org/10.1016/S1473-3099(16)30257-2 PMID: 27866944

22. Lee CR, Lee JH, Park KS, Kim YB, Jeong BC, Lee SH. Global dissemination of carbapenemase-producing Klebsiella pneumoniae: epidemiology, genetic context, treatment options, and detection methods. Front Microbiol. 2016;7:895. https://doi.org/10.3389/fmicb.2016.00895 PMID: 27379038

23. Berrazeg M, Diene S, Medjahed L, Parola P, Drissi M, Raoult D, et al. New Delhi Metallo-beta-lactamase around the world: an eReview using Google Maps. Euro Surveill. 2014;19(20):20809. https://doi.org/10.2807/1560-7917.ES2014.19.20.20809 PMID: 24871756

24. Egli A, Blanc DS, Greub G, Keller PM, Lazarevic V, Lebrand A, et al. Improving the quality and workflow of bacterial genome sequencing and analysis: paving the way for a Switzerlandwide molecular epidemiological surveillance platform. Swiss Med Wkly. 2018;148:w14693. https://doi.org/10.4414/ smw.2018.14693 PMID: 30552858

\section{License, supplementary material and copyright}

This is an open-access article distributed under the terms of the Creative Commons Attribution (CC BY 4.0) Licence. You may share and adapt the material, but must give appropriate credit to the source, provide a link to the licence and indicate if changes were made.

Any supplementary material referenced in the article can be found in the online version.

This article is copyright of the authors or their affiliated institutions, 2021. 